\title{
Erratum: Geniposide ameliorates TNBS-induced experimental colitis in rats via reducing inflammatory cytokine release and restoring impaired intestinal barrier function
}

Bin XU, Yan-li LI\#, Ming XU, Chang-chun YU, Meng-qiao LIAN, Ze-yao TANG, Chuan-xun LI, Yuan LIN*

Acta Pharmacol Sin 2017; 38 (5): 688-98.

The concentration of geniposide $(25-100 \mu \mathrm{mol} / \mathrm{L})$ in PubMed is wrong.

The correct concentration is geniposide $(25-100 \mu \mathrm{g} / \mathrm{mL})$.

The editors are sorry for the error. 